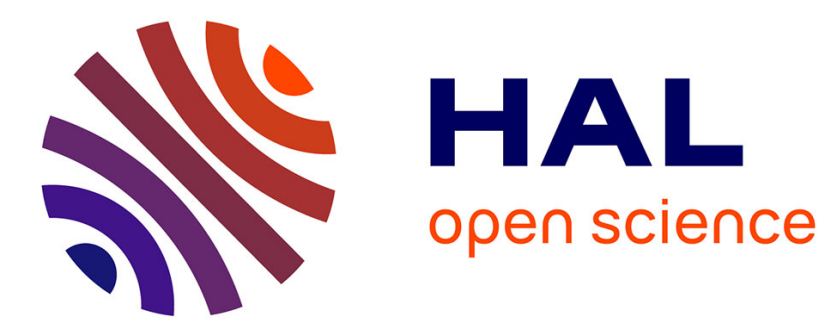

\title{
Abstract Algebra Teaching and Learning
}

Thomas Hausberger

\section{To cite this version:}

Thomas Hausberger. Abstract Algebra Teaching and Learning. Steve Lerman. Encyclopedia of Mathematics Education, Springer, 2018, 978-94-007-4977-1. 10.1007/978-3-319-77487-9_100022-1. hal-01865229

\section{HAL Id: hal-01865229 \\ https://hal.science/hal-01865229}

Submitted on 20 Feb 2021

HAL is a multi-disciplinary open access archive for the deposit and dissemination of scientific research documents, whether they are published or not. The documents may come from teaching and research institutions in France or abroad, or from public or private research centers.
L'archive ouverte pluridisciplinaire HAL, est destinée au dépôt et à la diffusion de documents scientifiques de niveau recherche, publiés ou non, émanant des établissements d'enseignement et de recherche français ou étrangers, des laboratoires publics ou privés. 
Abstract Algebra TeACHING AND LEARning

\section{Affiliation}

Thomas Hausberger

Institut Montpelliérain Alexander Grothendieck, Université de Montpellier \& CNRS,

Montpellier, France

thomas.hausberger@umontpellier.fr

Keywords

Abstract Algebra; Modern Algebra; Group Theory; Ring Theory; Field Theory; Algebraic structures; Mathematical structuralism; Axiomatic method; Conceptual mathematics; Mathematical abstraction; University Mathematics Education

\section{Definition}

As a mathematical discipline, Abstract Algebra, also called modern algebra or structural algebra, denotes, by opposition to classical algebra which focuses on formal manipulation of abstract symbols in relation to solving equations, the new image of algebra that emerged at the turn of the $20^{\text {th }}$ century. It was first presented in history in the textbook Moderne Algebra (Waerden 1930) which "inverted the conceptual hierarchy of classical algebra" (Corry 2016) by putting algebraic structures to the fore and seeing properties of numbers, polynomials, etc. as consequences of what is known on general structures rather than the other way round.

In an educational context, Abstract Algebra usually designates an upper division undergraduate course typically required for mathematics majors and centered on the structures of groups, rings, and fields. In general, it is encountered by students upon completion of courses in Linear Algebra. Abstract Algebra courses are thus taught at the transition between undergraduate and graduate studies and range from introductory to more advanced courses related to Galois Theory, Algebraic Number Theory, Algebraic Geometry, Homological Algebra or even Category Theory as a general theory of structures.

\section{Historical and epistemological landmarks}

According to historians (Wussing 2007), the recognition of the central role played by the group concept in permutation theory (Galois) and in the unification of the different geometries (Klein) allowed the development of the group structure as the first abstract mathematical structure, before the beginning of the 20th century. The unification of the different historical sources of groups was operated by Dyck who introduced the abstract group concept from generating operations and the consideration of their mutual relations. The systematization of the axiomatic method promoted by Hilbert also played a major role in establishing the formal, abstract and relational point of view.

Fields were introduced by Dedekind in 1871 to designate finite field extensions of the rational numbers (number fields), together with the concept of ideal (a rewriting of Kummer's theory of ideal numbers aiming at the generalization of the fundamental theorem of arithmetic). Finite fields originate both from the work of Galois and the theory of polynomial congruences by Gauss. Also influenced by the appearance of $p$-dic fields (Hensel), Steiniz developed in 1910 a general theory of fields which were classified according to their characteristic and the notion of prime field. Rings were previously introduced by Hilbert in 1900 as synonyms for the rings of integers of number fields. Hilbert did neither relate his notion to groups or fields, nor drew connections with polynomials.

The idea of algebraic structures as a unifying principle was due to Noether in the 1920s: she got Abstract Algebra away from thinking about operations on elements (such as addition or multiplication in groups or rings) but described structures in terms of selected subsets (such as normal subgroups of groups or ideals in Ring Theory) and homomorphisms. Noether and her school thus changed the way theorems were proved in algebra, focusing on general proofs that limit the calculations and put to the fore the "most general and fundamental" (hence simpler, according to structuralist views) concepts. This mathematical refoundation of algebra brought forward a new vision of mathematics as a discipline and paved the way for unprecedented 
mathematical constructs. The use of the axiomatic method to elaborate and apply structuralist concepts is well described in the Bourbaki (1950) Manifesto, written by a group of French mathematicians who were the great promoters of structuralist thinking. Indeed, Bourbaki set out to apply the methodology developed by the German algebraists to all fields of mathematics.

\section{Structures in Mathematics Education}

Mathematical structuralism inspired other scientific fields, including human sciences (psychology, sociology, etc.). It also led to the New Math (or modern math) reform of secondary education in the 1960s in the US, France, Germany and other countries. In many countries, the way mathematics was taught changed dramatically (for a period of about 20 years, until the reform was abandoned) with a focus on mathematical formalism through elementary aspects of Set Theory, symbolic logic and Abstract Algebra. Emphasis was put on the teaching of mathematical structures, hence the development of research aiming at the investigation of the abstraction processes involved in the conceptualization of these structures.

This paragraph focuses on theoretical elaborations in University Mathematics Education (UME) that deal with structures and abstraction, in connection with Abstract Algebra.

\section{Idealisation, thematisation and reflective thinking}

According to French philosopher Cavaillès, the abstraction involved in structuralist thinking decomposes into two fundamental processes, idealisation and thematisation (Sinaceur 2014). Cavaillès' account of algebraic structuralism as a philosophical dialectic between form and matter much inspired the psychologist Piaget. The latter considered that the whole of mathematics may be thought of in terms of the construction of structures according to "reflective abstraction", which he saw as an encapsulation of forms as new contents. From this trend follows the encapsulation of a process into an object as described by Dubinsky (1991) in APOS theory. Recently, Hausberger (2017a) developed epistemological and didactical aspects of thematisation in Abstract Algebra with a focus on the homomorphism concept.

\section{$\underline{\text { Structures }}$}

In the process-object duality, the structural aspects characterize the object dimension, so that the duality is also called procedural-structural. Simpson and Stehlíková (2006) have explored the acquisition of "structural sense" in relation to "coming to understand a commutative ring". They pointed out several "shifts of attention" required for the transition to abstract structures and focused especially on the shift from "particular objects and operations to the interrelationship of objects caused by the operations", as a consistent pattern.

In his phenomenological approach of structures (geometrical, topological, algebraic, etc.), Freudenthal (1983) insists that structures be "put into geometrical context" in view to the need and fruitfulness of representations in space to develop intuitions. He sees structures as "tools to organize the phenomena of the physical, social and mental world". Uncovering the idealisation process thus amounts to determining the phenomena that given structures organize. Hausberger (2017b) regards the meta-concept of structure itself as an organizing principle that governs thematisation, the second process of abstraction, which may be seen as a vertical mathematization (in the sense of Realistic Mathematics Education, RME) specific to the structuralist methodology.

\section{FUGS concepts and didactical consequences}

The historical landmarks have underlined the FUGS (formalizing, unifying, generalizing \& simplifying) character of Abstract Algebra concepts. Obstacles towards teaching strategies that rely on traditional didactic tools such as the Theory of Didactical Situations can be analyzed as consequences of their epistemological nature as FUGS. For instance, Dorier (1995) points out the difficulties to find, if any, a "fundamental situation" able to introduce the central concepts of Linear Algebra or similar concepts created on the basis of similarities between various mathematical objects. He thus advocates for the use of the "metalever", in fact to develop meta aspects in the teaching and learning of Abstract Algebra related to the axiomatic method and structuralist methodology. The existence of "fundamental situations" for FUGS concepts is still nowadays debated inside the 
UME community: for instance, Bosch et al. (2018) argue that a counting problem like the enumeration of the symmetries of a square may play the role of fundamental situation in the case of the group structure.

\section{Instructional approaches}

Fukawa-Connelly et al. (2016) have shown a strong inertia in the US among Abstract Algebra instructors: these rarely adopt new pedagogical approaches (lecture is predominant) and make very little usage of existing reform materials provided by UME research, despite the dissemination efforts. These findings probably reflect the situation worldwide.

This paragraph accounts for the main instructional approaches experimented in UME research and their results. These studies essentially focus on the teaching and learning of Group Theory (GT), with the exception of Hausberger who considers Abstract Algebra at large through the analysis of structuralist thinking and praxeologies.

\section{A cognitive approach with the support of technology}

A long-term project has been launched in the US in the 1990s by Dubinsky and his colleagues (Dubinsky et al. 1994) on the teaching and learning of undergraduate mathematics, and in particular GT, using the APOS framework both to explore errors and misconceptions and to design new approaches. They proposed "genetic decompositions" of main GT concepts, in particular working with cosets in quotient groups, and elaborated teaching sequences organized around computer experiences followed by discussion and then formal definitions. As an example of robust findings, the encapsulation into an object of the process of forming cosets appeared as a major issue. The teaching method was based on the premise that implementing algorithms fostered the construction of concepts in the learner's mind. The ISETL programming language was chosen for its proximity with the mathematical constructs (sets, functions, logical expressions).

\section{Guided reinvention of Abstract Algebra concepts}

More recently, Larsen (2013) launched the Teaching Abstract Algebra for Understanding project, focused on the creation of a research-based inquiry-oriented curriculum for Abstract Algebra. The instructional design was based on the RME framework and centered on GT, whose phenomenological roots where found, following Freudenthal, in symmetries of geometric figures. Under the guidance of the teacher, students described the set of symmetries preserving a triangle, developed a calculus for computing their combinations and axiomatized the set of rules that governed the algebraic computations. The system thus obtained was later applied as a model for reasoning in similar contexts (e.g. symmetries of a square) and culminated with the "reinvention" of the definition of a group. A similar process was used to handle quotient groups and the isomorphism concept in GT.

\section{$\underline{\text { Structuralist thinking and praxeologies }}$}

From the theoretical perspective of the Anthropological Theory of the Didactic (ATD) and in view of the methodological dimension of structuralist thinking, Hausberger (2018) introduced the notion of structuralist praxeology. These praxeologies are shown to be developed in conjunction with a dialectic of the particular and the general that Hausberger called "objectsstructures dialectic": axiomatic structures may be applied as a conceptual generalizing-simplifying viewpoint in order to demonstrate properties on mathematical objects and, conversely, a semantic control of the formal general statements on structures is exercised by putting them to the test of known examples. Praxeological models of the (across university) concrete to abstract transitions in Abstract Algebra are given in order to understand difficulties met by students from an institutional perspective and new inquiry-based instructional approaches are presented in terms of study and research paths.

Semiotic, phenomenological and didactical aspects of the objects-structures dialectic are developed in Hausberger (2017b). As a piece of didactical engineering dedicated to facilitate the appropriation of structuralist thinking and the meta-concept of structure by students who were already taught GT, Hausberger invented a new mathematical structure, that of a "banquet", that has phenomenological roots, bears similarities with permutation theory and is well-adapted to classroom discussion of structuralist views using the meta-lever. 


\section{Conclusion}

The teaching and learning of Abstract Algebra has been investigated in UME through different lenses (epistemological, cognitive, phenomenological, institutional, etc.), focusing on students' difficulties and abstraction processes required for its learning, the rationale of given structural concepts, or the inertia of teachers' practices. With its double movement of abstraction, idealisation and thematisation, it offers many challenges to researchers in order to develop inquiry-based approaches eager to promote adequate conceptualization and understanding. Altogether, research in this area remains limited and several issues would need to be more systematically investigated: If phenomenological roots of GT are found in symmetries, what about Ring Theory and Field Theory? What would be sustainable study and research paths? What usage of CAS technologies? What reform for Abstract Algebra, including the reorganization of syllabus across undergraduate and graduate studies, to tackle the observed persistent difficulties?

Cross-References

Abstraction in Mathematics Education

Actions, Processes, Objects, Schemas (APOS) in Mathematics Education

Anthropological Theory of the Didactic

Algebra Teaching and Learning

Concept Development in Mathematics Education

Didactic Situations in Mathematics Education

Linear Algebra Teaching and Learning

Logic in University Mathematics Education

Mathematical Approaches

Realistic Mathematics Education

University Mathematics Education

\section{References}

Bourbaki N (1950) The architecture of mathematics. Amer Math Monthly 4(57):221-232.

Bosch M, Gascón J \& Nicolás P (2018) Questionin Mathematical Knowledge in Different Didactic Paradigms: the Case of Group Theory. Int J Res Undergrad Math Ed 4(1):23-37.

Corry L (2016) Algebra. In: Encyclopædia Britannica. https://global.britannica.com/topic/algebra/Structural-algebra. Accessed 11 March 2018.

Dorier J-L (1995) Meta level in the teaching of unifying and generalizing concepts in mathematics.Educ Stud Math 29:175197.

Dubinsky E, Dautermann J, Leron U \& Zazkis R (1994) On learning fundamental concepts of Group Theory. Educ Stud Math 27:267-305.

Fukawa-Connelly T, Johnson E \& Keller R (2016) Can Math Education Research Improve the Teaching of Abstract Algebra? Notices of the AMS 63(3):276-281.

Freudenthal H (1983) Didactical phenomenology of mathematical structures. Reidel, Dordrecht.

Hausberger T (2017a) The (Homo)morphism Concept: Didactic Transposition, Meta-Discourse and Thematisation. Int J Res Undergrad Math Ed 3:417-443.

Hausberger T (2017b) Enseignement et apprentissage de l'algèbre abstraite à l'université et premiers éléments d'une didactique du structuralisme algébrique: études croisées en didactique et épistémologique des mathématiques. Note de synthèse pour l'habilitation à diriger des recherches. Montpellier: Université de Montpellier. Retrieved from https://hal.archives-ouvertes.fr/tel--01408565. 
Hausberger T (2018) Structuralist Praxeologies as a Research Program on the Teaching and Learning of Abstract Algebra. Int J Res Undergrad Math Ed 4(1):74-93.

Larsen S (2013) A local instructional theory for the guided reinvention of the group and isomorphism concepts. J Math Behav 32(4):712-725.

Simpson A \& Stehlíková N (2006) Apprehending mathematical structures: a case study of coming to understand a commutative ring. Educ Stud Math 61:347-371.

Sinaceur, H. (2014). Facets and levels of mathematical abstraction. Philosophia Scientiæ, 18(1), 81-112.

Waerden BLv. (1930) Moderne Algebra. Springer, Berlin.

Wussing H (2007) The Genesis of the Abstract Group Concept. Dover Publications. 